\title{
Structural and semantic characteristics of English complex sentences with object clauses
}

\author{
Durus Kozuev - Nazgul Dzharkinbaeva
}

DOI: 10.18355/XL.2021.14.02.15

\begin{abstract}
In modern linguistics, the functional and communicative side phenomena are growing towards the pragmatic aspect of the language. However, the problem of the relationship between meaning and its expression still remains in the focus of linguists' attention. The problem of characterizing sentences in linguistics has not yet been analyzed. This research is the first instance of a systematic study of syntactic structures and ways of expressing in the language. In this case, the main emphasis is on communicative, formal, and functional-semantic statements. The article is devoted to the structural-semantic description of complex English sentences with object clauses. It focuses on the fact that these sentences are characterized by a full subjectpredicate structure in its constituent parts: at the main sentence and subordinate clause. Note that complex sentences follow the English two-part sentence's rigorous principle: both the subject and the predicate. The relevance of the research topic is determined by the fact that the study of structural and semantic features of syntactic units of various levels in linguistics has a unique scientific and theoretical significance. Learning Sentences in Linguistics began quite a long time ago; however, a comparative analysis of a simple one-compound English sentence has not become the object of special research up until now. The proposal is understood as a central object, and a comprehensive revealing of its essence is one of the difficult problems that need to be solved.
\end{abstract}

Key words: complex sentence, object clause, subordinating conjunctions, predication, nomination, proposition

\section{Introduction}

In its most general form, a complex sentence is defined as "an integral syntactic structure of a higher (as compared to a simple sentence) order, which is not a union of sentences, but two or more predicative parts (which are subordinate to each other) and serving as one communicative unit" (Tsarikaeva 2012: 376).

The selection of complex sentences with object clauses in English is not associated with theoretical and practical difficulties in their description. Almost all Anglicists recognize the existence of this kind of complex sentence. "Object clauses perform in a complex sentence the function of the direct or prepositional indirect object. They answer the questions What, About what, For what, etc., object clauses are combined with the main clause with the same conjunctions as the subordinate subjects and predicates" (Kachalova, Izrailevich, 1995: 50; Belyaeva, 1997: 275-276.)

The subordinating conjunctions for the connection of the main and the subordinate clauses in complex sentences with object clauses are: that, whether, if; allied words used for this purpose are: who (whom), whose, what, which, which, where, how, why. For example:

(1) "Not a day goes by that the media of European, American, and Asian countries do not cover this problem."

(2) "Now I want to go back a little and tell what happened at the garage after we left there the night before"(Fitzgerald, 2014: 238). 
(3) "I'll ask him to find out where they live," Sergeant Watkins said (Bowen, 1998, p. 113).

In the 1st English example, the object clause introduced by the subordinating conjunction that supplements, as it were, the whole meaning of the main sentence Not a day goes by; in the 2nd English complex sentence, the object clause introduced by the conjunction what complements and reveals the content of the second homogeneous predicate verb want to tell; in the 3rd example, the object clause will also help the verb to find out and introduced by the conjunction where.

Thus, the main criterion for identifying complex subordinates' English language with object clauses in these subordinate clauses' object, namely, to act as part of a direct or indirect prepositional object in a complex sentence.

In this regard, this work's primary goal is to study the constituent parts of complex sentences' structural and semantic relations with object clauses in the English language.

\section{Principles of classification of English complex sentences with the object clause}

When classifying English complex clauses with a subordinate clause, we were guided by the following principle of subdivision of subordinate clauses in their composition: "the subordinate clause performs in a complex sentence the function of one of the members of the sentence: subject, nominal part of a complex predicate, object, definition and circumstances" (Kachalova, Izrailevich, 1995: 46). We also added one more relevant criterion: "Subordinate clauses usually answer the same questions as the members of a simple sentence, and are, as it were, expanded members of a simple sentence. There are as many types of subordinate clauses as there are members of the sentence" (Kachalova, Izrailevich, 1995: 46).

The subordinate clause identifies the subtype of English complex clauses with object clauses. This subordinate clause answers the oblique case questions with and without prepositions and is structurally and grammatically "... a descriptive replacement of the object missing in the main sentence" (Rosenthal, Telenkova, 1985: 236; Onysko 2004: 2422). For example:

(4) "They began from the fact that terror is acceptable in societies with tyrannical regimes that do not give their citizens legal means (within the framework of the parliamentary process and democratic procedures) to fight for the adoption of their ideals and a restructuring of society."

(5) "All through supper, he was in such a good" aunt thought "what had happened to the child" (Twain 2012: 36) - "During dinner, he was in such a wonderful frame of mind that the aunt wondered "what happened to the child."

(6) "Huckleberry was free to do everything he liked" (Twain 2012: 66) "Huckleberry could do whatever he wanted."

Object clauses are attached to the main clause not only through conjunctions (example (4), in which the subordinate conjunction that is used) but also through connective words (example (5), in which the conjunction what is used) and also in an asyndetic way. In contrast, such a way tends to express elucidability since, in this case, only the subordinate conjunction that is omitted: "Object clauses can join the main one without the conjunction that." (Belyaeva 1977: 276). For example (5), the subordinate clause he liked is attached to the main in an asyndetic way by omitting the subordinate conjunction.

However, the subtype of English complex sentences with a subordinate clause (Object Clauses) merges with complicated English sentences with a complex object (Complex Object).

English complicated sentences are composed of three types of complex object: A) A complex object, consisting of a direct object + infinitive: I want to learn this poem by heart - this poem by heart; B) Complex object, consisting of direct object + present or past participle: We heard her singing a beautiful song - We hear how she sang a 
beautiful song; They watched the letters posted -; and C) Complex object, consisting of a direct object + past participle when an outsider acts on the request or order of the main character: He will have his hair cut - He will be shaved (Gruzinskaya, Cherkasskaya 1956: 238-239; Smirnitsky 1957: 264-265; Kachalova, Izrailevich 1995: 22).

However, two distinctive features separate English complex sentences with object clauses and English expanded sentences in different syntactic classes. Firstly, the English complex object as part of the expanded sentence has one of the non-finite verb forms: the infinitive, the present participle or participle, the sign of its difference from the English complex clause with a subordinate clause, which has only finite verb form [example (4), (5), (6)]. Secondly, the finite form of the predicate from the object motivates the phenomenon of predication and places not only the given subordinate clause but also everything that is complexly subordinated to the realm of real being: "It is predication that includes what is said in the system of being, gives the utterance completeness and turns this segment of speech into a sentence" (Smirnitsky 1957: 102); while English sentences with complex objects with non-finite verb forms as part of extended sentences, the phenomenon of predication itself do not in any way motivate the occurrence.

\section{Structural and semantic description of the structure of Complex Object}

The subordination determines the structural and grammatical organization of English complex objects that the subclause manifests with the main one.

Several lexical-semantic classes of English verbs can be distinguished (in the position of the predicate in the finite form, and the position of other members of the sentence in the non-finite form), in which object clauses are used - verbs of speech: tell, say, inform, etc.; verbs of feelings and perception: observe, remark, notice, feel, hear, see, etc.; verbs of thought and mental activity: consider, conceive, believe, etc.; verbs of request or expression of wish: beg, ask, etc.; verbs with the modal meaning of a proposal, desire, intention: intent, suppose, hope, wish, etc.; verbs of specific actions: do, take, buy, etc. (Kachalova, Izrailevich 1995: 52; Tolengutova, 2008: 19; Shemshurenko 2012: 18). Here are some examples:

(7) "Meg said that she felt tired" (Welch 2005, p. 147) - "Meg said she was feeling tired."

(8) "The old lady turned around quickly to look what was there, and the boy ran away, climbed up the high fence, and disappeared over it." [Twain 2012: 6] - "The old woman hastily turned around to see what was there, and the boy ran away, jumped over the fence and disappeared behind him."

(9) "I think I have made a mistake in my calculations," Sergeant Watkins said" [Bowen: 149] - "I think I made a mistake in my calculations," said Sergeant Watkins. “

(10) "So I thought you ought to know something about me" (Fitzgerald, 2014: 96) "And so I decided that everyone should learn more about me."

(11) "The boys had not noticed the noise had stopped a while before when the teacher came up and stood over them." (Twain 2012: 84) - "The boys did not notice that the noise had stopped shortly before, as the teacher approached them and stood beside them."

In the English complex sentence (7), the object clause is connected to the main clause through the subordinate conjunction that with an additional-explanatory meaning; in the English complex sentence (8), the object clause is connected to the main one through the conjunction of what with an explanatory-interrogative purpose. In the three subsequent English complex sentences (9), (10), and (11), object clauses are attached to the main clause in an asyndetic way. At the same time, it is implied that

XLinguae, Volume 14 Issue 2, April 2021, ISSN 1337-8384, eISSN 2453-711X 
the additional explanatory conjunction omitted that is: "Object clauses can be attached to the main without that." (Belyaeva, 1977: 276).

This relevant omission and meaningful absence of any grammatical form of a word, grammatical link, or grammatical affix are designated as "zero form." "The general name of the absence of forms, which acquires grammatical meaning in opposition to similar positively expressed forms" (Rosenthal, Telenkova,1985: 154).

Secondly, this is the so-called event nomination, which is in a complex sentence, namely, in a complex sentence with an object clause, we establish according to three criteria. 1) The first criterion is the event position as the highest abstracted degree of predicative relations, linking two complete predications: two full-component subjectpredicate structures. 2) the second criterion pertains to speech situations denoted in two sentences: the main and object clauses have their extra-linguistic grounds, i.e., concepts do not depend on each other, although in the proper grammatical respect, they are not entirely independent. 3) The third criterion requires that both speech situations, which are realized in the main clause and the subordinate clause, constitute a complex structure for the designation of an integral event, the components of which are, as it were, cemented by relations of subordination of the aspect of the sentence to the main one. Here we have the nominative aspect of the sentence "... studying the ways of designating integral events... The term 'propositive nomination' will be applied to the nominative aspect of the sentence 'its derivatives"' (General linguistics ... 1972: 299).

However, each English complex sentence with an object clause is characterized by a full subject-predicate structure in its constituent parts: both in the main sentence and the subordinate clause of our examples (7) - (11). The English analytical twocomponent sentence's strict principle operates in all the above English complex sentences in their constituent parts. There is both a subject-noun and a predicate-verb: [Subject Pred.] which are connected by relations of complete predication:

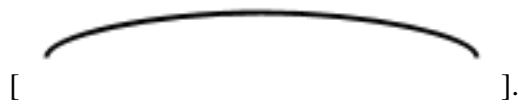

The conceptual and semantic formula of an English complex sentence with a subordinate clause looks as follows:

English SPP

with:

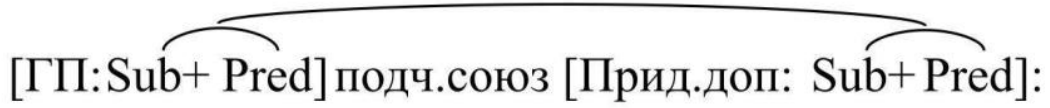

Let us designate the content of our signs and symbols:

SPP - a complex sentence,

Pred. the object clause,

GP - main clause,

Sub-conjunction - subordinate conjunction,

Sub - subject (subject-noun),

Pred - predicate (predicate-verb),

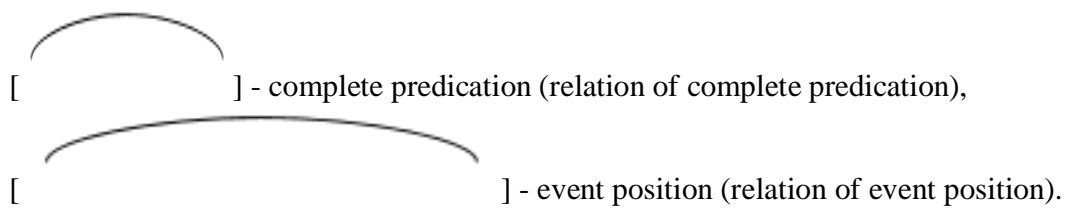

"Event position," which we will consider based on examples (7) - (11):

\section{(7) [Meg+said] that [she+felt]}




\section{(8) [The old lady + turned around $]$ what $([$ (what) was there $]$}

The two-part nature of the English complex sentence in example (7) determines the presence in both components: in the first main clause and the second object clause the presence as a subject-noun and predicate-verb.

Similarly, this two-part principle is not violated in the constituent parts of the English complex sentence (8), in which in its subordinate conjunction what plays a double semantic-grammatical function: firstly, it plays the role of subordinateexplanatory conjunction, and secondly, it plays the role of the subject in the structure of the clause (Azarova 1968: 22).

Both in the English complex sentence (7) and the complex sentence (8), their complex sentences unite their compulsory subjects and predicates by predicative relations of complete predication, which is "... The connection of the content of the expressed to reality. It is predication that fulfills what is said into a system of being that gives the utterance completeness and turns this segment of speech into a sentence." (Smirnitsky 1957, p. 102).

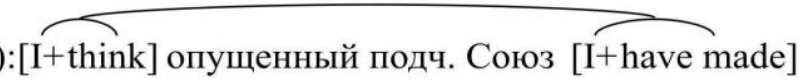

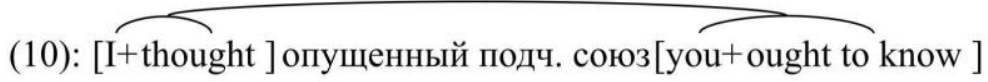

(11): [the boys+had not noticed] опущенный подч. союз [the noise+ had stopped].

In the English examples (9), (10), and (11), we note two relevant factors that, to one degree or another, find their places in the semantic and grammatical structures of the entire complex sentence, firstly, it is the omitted subordinate explanatory conjunction that, which, in the essence of the analytical linguistic type of an English sentencestatement, may often not be used, but its implicit presence in the semantic structure of the entire complex sentence does not raise any doubts (Belyaeva 1977: 276; Johanson 1994: 77). In linguistics, the object clauses applied to all varieties of the predicate or to another member of the sentence expressed by the non-finite verb forms, conveying the content of speech, thought, feeling, or description of the object - the object of the action (Zhigaldo, Ivanova, Iofik 1956: 322; Akhmetzhanova 2005: 346).

When analyzing the structural and semantic characteristics of complex sentences, the term "complete proposition" is also used to denote prepositive relations arising between components with a full-constituent subject-predicate structure, and therefore, with full predication, in the structure of asyndetic complex sentences and compound sentences. The term "complete proposition" is used based on relatively semanticgrammatical free relations that arise between the components of asyndetic complex sentences and compound sentences, compared with the type of complex sentences in which already arise between the main clause and the subordinate clause non-free, semantically-grammatically regulated relations. Moreover, for complex sentences with their constituent parts, explicating complete predication, we choose the term "event proposition."

So, in examples (7) - (11), there is an event proposition that performs, firstly, a complex conceptual-semantic phenomenon, the components of which are connected in the language by a regulated subordination, namely, subordinative-complementary relations; and, secondly, they differ from the concept that constitutes the main core of

XLinguae, Volume 14 Issue 2, April 2021, ISSN 1337-8384, eISSN 2453-711X 
the event proposition that arises between the two components of a complex sentence with an object clause.

As a result of comparing sentences with a plural object with different types of predicates, it was found that the undifferentiated characteristic of subjects is determined by the semantics of compatibility and reciprocity of action (relationship). The first feature is a broader concept, as it is expressed by transitive and intransitive verbs when describing the effect of subjects on an object and the compatibility of movement or location. Reciprocity is a special case of undifferentiated characteristics of subjects when subjects act on each other.

The expression of the sign of the compatibility of the action depends on the semantics of the predicate forming the construction and on the dismemberment / indivisibility of the characteristics of the object. The latter is determined by means of the context or the corresponding circumstances. At the same time, it is necessary to distinguish the sign of the joint influence of subjects on the object, which determines the undifferentiated characteristics of the subjects and the semantic simplicity of the structure, from the description of the joint participation of the subjects in one process not related to the common object, when each of the subjects does his own thing, i.e., is characterized by an individual characteristic.

The main conditions for expressing the general, aggregate characteristics of subjects, due to semantics, reciprocity, is the designation of all participants in the event with a name(s) in the position of the subject and the functioning in the construction of this type of reciprocal verbs and verbs participating in the expression of the indicated attribute in combination with the appropriate circumstances.

As a result of the study, it was also established that not every mutual or joint characteristic of subjects is a reflection of the term conjunction. The polysemy of constructions with each other revealed the ability of each of them to express the individual characteristics of the subjects, i.e., sentential conjunction. Cases of designating several events with the construction $C$ together AND each other can be called "false" compatibility and "false" reciprocity. The manifestation of this feature is associated with the functioning in construction with the verbs of movement, physical perception, thinking, interpersonal relationships. In addition, sentences with verbs characterizing the beginning of an action or the simultaneity of action express the individual characteristics of the subjects and describe the internal and external properties of objects.

\section{Conclusion}

English complex sentences with an object clause answer questions of oblique cases without prepositions and with prepositions and are structurally and semantically an extended replacement for the object missing in the main sentence. The English subordinate clause can be joined to the main one through subordinate-explanatory conjunction that or through other conjunctions, or even directly without using the conjunctions that and which, due to the similarity of the English syntax, can be omitted.

The two-component nature of an elementary English sentence, namely, the obligatory presence of a subject and a predicate, predetermines a full-component subjectpredicate structure, which, in turn, causes a full-valued, complete predication to linguistic reality in each of the constituent parts of an English complex sentence with object clause. Complete predication, which is realized at the level of predicative relations in the structure of complex sentences as part of a complex one: the main and object clauses are transformed when they are combined, into one structural-semantic whole into a predicative relation of a more highly abstracted type - into an event proposition. This event proposition is characteristic of compound sentences in which the conceptual and semantic connection between compound sentences is more sophisticated and closer than the conceptual and semantic connection between 
compound sentences in the types of compound sentences: in the asyndetic complex and the compound sentences, in which similar positive relationships are characterized as complete and incomplete ones.

The study of the designation of one or more events with one construction, corresponding to the general course of modern linguistics on the study of the semantic content of syntactic units, reveals one of the most common mechanisms of the semantic and syntactic organization of a sentence. Conducted in accordance with the basic laws of Marxist-Leninist philosophy, the study of linguistic patterns in the designation of the dismembered and common features of the multiple subject contributes to a deeper understanding of the essence and characteristics of the interaction of language and thinking. As a result, sentences with a multiple subject appear as one of the active means of designating individual and aggregate (common) characteristics of subjects.

The complex mechanism of the syntactic and semantic organization of sentences with a plural subject determines their ability, under certain conditions (a certain lexical content), to semantically correlate with a complex sentence (sentence conjunction) or not correlate with it (term conjunction). The proposal, accordingly, contains information not only about the attitude of the subjects to the action being taken but also about the attitude of the subjects to each other.

The presence of a plural subject, expressed by a plural noun, composition of nouns, or a noun with a quantitative determinant, is a condition that allows this construction to denote several events.

The criterion of semantic complexity adopted in this work - the type of conjunction serves as the basis for qualifying monopredicative sentences as ambiguous since the complexity (or simplicity) in this case will depend on the nature of the predicative feature. The use of this criterion, based on the formal features of constructions for the analysis of other types of sentences, would make it possible to create a semantic classification of sentences in the modern English language.

\section{Bibliographic references}

AZAROVA, L.V. 1968.Transformations of a complex sentence with an object clause in modern English. author. diss. Cand. philol. sciences. 22 p.

AKHMETZHANOVA, Z.K. 2005. Comparative linguistics: Kazakh and Russian languages. Almaty: KAZGUM and MO them. Abylai Khan, 373 p. ISBN 978-9668736-05-6

BANASOVA, M. H. 2018. Prepositional word combinations with modal meaning. In: Xlinguae, vol 11, n. 3. pp.51-66.

BAGHANA, J. - OGNEVA, E. A. - VOlOSHINA, T. G. - MIRONOVA, G. V. NOVAKOVA, K. S. 2020. Dialogical speech as a field of compound-complex sentence communicative types application. In: Xlinguae, vol. 13, n.2. pp.235-244.

BAGHANA, J. - VOLOSHINA, T.G. - NOVAKOVA, K.S. 2019. Morphological and syntactic interferrence in the context of franco-congolese bilingualism. In: Xlinguae, vol.12, n.3, pp.240-248.

BELYAEVA, M.A. 1977. English grammar. Textbook. 6th ed. In: Higher School, 333 p. ISBN 5-02-033329-8

BOWEN, R. 1998. Evans Above. New York: Berkley Prime Crime, 214 p. ISBN 0425166422

FITZGERALD, F.S. 2014.The Great Gatsby. Moscow: Eksmo, 304 p. ISBN: 978-504-105379-6.

GENERAL LINGUISTICS: The internal structure of the language. Moscow, In: Nauka, 1972.565 p. ISBN 5-89464-010-5

GRUZINSKAYA, I.A. - CHERKASSKAYA, E.B. 1956. Grammar of the English language. 16th ed. In: Gosuchpedgiz, 255 p. ISBN 5-88682-027-2.

XLinguae, Volume 14 Issue 2, April 2021, ISSN 1337-8384, eISSN 2453-711X 
JOHANSON, S. - HOFLAND, K. 1994. Towards an English-Norwegian parallel corpus. Amsterdam and Atlanta, 168 p. ISBN 9789027223005

KACHALOVA, K.N. - IZRAILEVICH, E.E. 1995. Practical grammar of the English language: in 2 volumes. T. 1. 8th ed. Kyiv: Methodology, 368 p. ISBN 978-5-99250716-4

KACHALOVA, K.N. - IZRAILEVICH, E.E. 1995.Practical grammar of the English language: in 2 volumes. vol. 2, 8th ed. Kyiv: Methodology, 304 p. ISBN 978-5-99250716-4

ONYSKO, A. 2004. Anglicisms in German: from iniquitous to ubiquitous, English today, vol. 20, n. 1, pp. 2421-2424. ISBN 978-5-04-198279-6.

ROSENTHAL, D.E. - TELENKOVA, M.A. 1985. Dictionary-reference book of linguistic terms. Pos. for the teacher. 3rd ed. Moscow, In: Education, 399 p. ISBN 506-000191-1

SMIRNITSKY, A.I. 1957. English syntax. In: Publishing house of literature on foreign languages, $286 \mathrm{p}$. ISBN 5-354-00600-7

SHEMSHURENKO, O.V. 2012. Isomorphism and allomorphism of a complex sentence in Russian, English and Turkish: author. diss. ... Cand. philol. sciences. Kazan, 22 p. 212.078 .03

TOLENGUTOVA, A.S. 2008. Structural, semantic and pragmatic features of a complex sentence in a business text (based on commercial correspondence): Avtoref. diss. Cand. philol. sciences. Almaty, 26 p.

TSARIKAEVA, F.A. 2012. Structural types of complex sentences. Bulletin of the North Ossetian State University named after Kost Levanovich Khetagurov. n. 2, pp. 374-378. ISSN: 1994-2796

TWAIN, M. 2012. The Adventures of Tom Sawyer. In: Publishing house "Eksmo", 288 p. ISBN 978-5-91921-127-3

WELCH, K. 2004. Autumn Promises. New York: Steeple Hill Books, 252 p. ISBN: 1932128-00-2

ZHIGALDO, V.N. - IVANOVA, I.P. - IOFIK, L.L. 1956. Modern English. The theoretical course of grammar: Textbook. In: Publishing house of literature on foreign languages, 350 р. УДК 881.11.

Words: 3970

Characters: 25646 (14,25 standard pages)

Assoc. Prof. Kozuev Durus

Vice-Rector for Academic Affairs,

Bishkek State University named after K. Karasaev

Bishkek,

720044, Chyngyz Aitmatov avenue, 27

Kyrgyzstan

bhu@bhu.kg

Dzharkinbaeva Nazgul

Bishkek State University named after K. Karasaev

Bishkek,

720044, Chyngyz Aitmatov avenue, 27

Kyrgyzstan

bhu@bhu.kg 